\title{
THE USE OF DIGITAL TOOLS FOR THE PRESERVATION OF ARCHITECTURAL, ARTISTIC AND CULTURAL HERITAGE, THROUGH THREE-DIMENSIONAL SCANNING AND DIGITAL MANUFACTURING
}

\author{
K. Moreno Gata ${ }^{1,2}$, E. Echeverría Valiente ${ }^{1}$ \\ ${ }^{1}$ Dept. of Architecture, University of Alcala, Alcala de Henares, Madrid, Spain ernesto.echeverria@uah.es \\ ${ }^{2}$ Visiting Researcher, Dept. of Architecture, Massachusetts Institute of Technology, Cambridge, Massachusetts, USA \\ kevinmg@mit.edu
}

KEYWORDS: laser scanning, computational design, 3d digital fabrication, heritage conservation, tombs, underground surveying

\begin{abstract}
:
Applications of 3dscanning and digital manufacturing established a new understanding of the architectural space, making it possible to capture it at a specific time. The possibility to get them closer ease the recreation of a physical object. In the present work, different methodologies and post-production techniques are presented, starting from scans, and working computationally to prepare the models for additive manufacturing. To describe this workflow, two architectural examples are used: a historic façade of the XVI Century and the recent archaeological project, from II Century BC. The primary objective has been to get closer the world of 3D scanning and digital manufacturing. It has been focused on its application for the preservation of fragile cultural elements, not only in its conservation from natural disasters or human conflicts but also to study the possibility of replicating the elements and making them accessible in a digital way.
\end{abstract}

\section{INTRODUCTION}

The use of digital tools in heritage intervention allows us to make progress in the understanding of a studied environment. Besides, 3dscanning it is not a new issue for preserving cultural heritage, Due to a large amount of data that it is possible to introduce in a three-dimensional model, it is reasonable that there is a tendency to use these techniques. Institutions also consider relevant the possibility to replicate their artifacts using scanning, such as Computer Tomography (CT) or 3D scanning, creating online repositories (British Museum et al, 2014), with the aim being able to exhibit more works without damaging them.

The proliferation of 3D scanning devices has made this practice a common activity in the field of virtual and physical replication of everyday objects. Consequently in their application for the preservation of heritage, Figure 1. 3D scanning produces a highprecision reference model with detailed information of the original shapes: depths and polychrome, generating masses of points that can be later turned into three-dimensional surfaces and meshes with which to work.
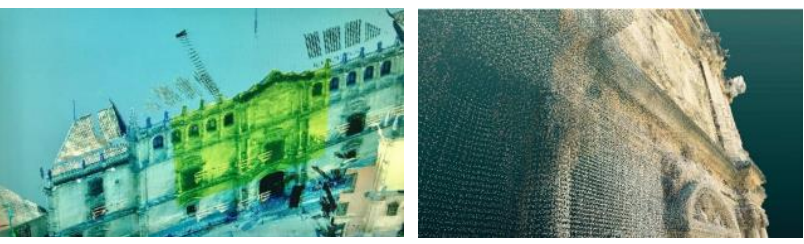

Figure 1: Façade University of Alcala. 3D scan by the Department of Architecture, 2016.

The work presented here suggests a workflow that starts from the point cloud of different scans. The available data is analyzed and coordinated, making a selection of the elements to be studied, to its three-dimensional mesh construction. Secondly, through 3D post-production, a selection and editing are done, repairing the mesh through a parametric algorithm that it is used to generate $3 \mathrm{dmesh}$, obtaining a reliable reproduction of the current state digitally. This workflow can be applied several times through the life of the monument, having a better understanding of it and generating a digital gallery for its conservation. The next natural step after generating the point clouds is to create $3 \mathrm{~d}$ models to work with and making feasible creating physical replicas. Unfortunately, a definite method has not yet been achieved. However, it should be easier to make accessible 3dscanining to fabrication. The computational work is tedious and timeconsuming. Having the possibility to create prototypes or scale models, have multiple advantages.

Additionally, a digital adaptation is made for the production of individual elements, creating replicable objects, through various additive 3D manufacturing systems.

In the first instance, during 2017 it has been studied the case of the Façade of the University of Alcala (Echeverria et al, 2017), 1553 A.D. Secondly, the same process has been applied to "The Tomb of Ipi", (Egypt, 2000 B.C.) (Figure 6) a recent archaeological project in the Kings Valley, contributing to the existing research of the Middle Kingdom Theban Project. The 3D schemes generated for this work complement the archaeological studies of the research project. For the first-time replicas of this architectural site are made, providing a better understanding of its geometries, that can allow us to percept the ancient archaeological excavations not only from a digital perspective but also to its digital fabrication, extending the heritage conservation possibilities. For that reason, special care has been taken in the final post-processing of the $3 \mathrm{~d}$ mesh.

During the computational work, the digital cleaning process has been improved since the Alcala's Façade, and several tools have also been developed, such a parametric algorithm that allows us to apply subdivisions of the mesh that the 3dscanning software generates, giving more flexibility in the faces dimensions or the pattern, depending on the input data to be chosen. Currently, the workflow allows us to produce physical objects, from $3 \mathrm{~d}$ printed models of specific elements, to 1:1 scaled elements, depending on the mesh resolution it is desired.

On the other hand, the versatility obtaining the results makes a call into question what real value of physical art objects has. It has seen how collective knowledge can be enriched through the free publication of these $3 \mathrm{D}$ documents on web platforms. It is also noticed that this workflow could be applied to many other purposes, including Computational Tomography (CT Scan), also studied by the authors.

The primary purpose of the work proposed here is the application of this workflow to fragile cultural monuments, not only to digital 
conservation of monuments against adverse effects but also to replicate them and present them to the public preventing the possible damage to make the monument accessible digitally.

\subsection{Previous work}

Earlier, collaborating with the Department of Architecture, of the University of Alcala, it has been studied the case of the Façade of the University of Alcala, 1553 A.D, (Echeverria et al., 2013) before his restoration in 2017, preserving his condition digitally, and having reliable physical documentation of the ancient building. During this time, a series of preliminary models was carried out, studying the possibilities that the digital fabrication of scale elements could give us.

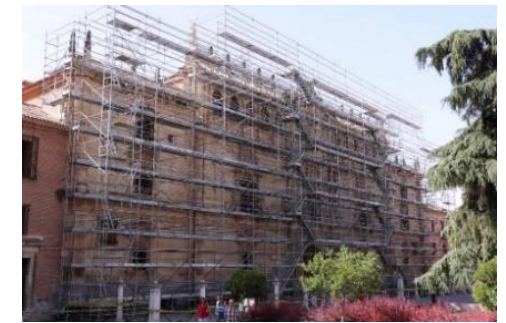

Figure 1: Façade University of Alcala. Restoration, 2017.

\subsection{Related works}

It is clear that there is a need to create libraries of architectural sites as well. From natural disaster to human conflicts, cultural heritage is at risk. At architectural scale, significant work has been done. Over the last decade, platforms like Cyark, have made possible the creation of $3 \mathrm{~d}$ laser scan records, to make them digitally accessible in the future. Besides, the popularization of photogrammetry free software, such 123Catch from Autodesk, allowed creating open source galleries of architectural spaces (Nagakura et al., 2013), doing merely the recreation of architectural space through photographs or videos taken with conventional technology.

The replication of objects through digital manufacturing is a practice that is also gathering great interest in archaeological aspects. It is worth noting the artistic installation of "The other Nefertiti" (Nelles, J et al., 2016), in which new considerations on the democratization of culture are addressed through the web publication of scanned artifacts. On the other hand, more systematically, it is the work of the Factum Foundation (Lowe et al., 2017), promoting a digital technology for recording, documentation, and dissemination of cultural heritage.

\subsection{D scanning methodologies}

Although there are multiple alternatives to study threedimensional surfaces through flat images or recordings taken from different positions, this work is focused on threedimensional laser scanning. Photogrammetry aims to study threedimensional surfaces through flat images or recordings taken from different positions. In a second point, that information processed and interpreted by different software or manually, allows us to create three-dimensional patterns and studies of the terrain, with topographical information previously taken. The taking of a large number of images through the object analyzed allows us greater accuracy in the generation of a 3D model. On the other hand, three-dimensional scanning is based on the direct projection of laser or infrared, measuring the distances of light beams automatically. With a single data collection, it would be enough to obtain a three-dimensional approximation.

During the process of postprocessing of the $3 \mathrm{~d}$ objects, it is considered that a digital repair is needed (Figure 2) to obtain three-dimensional meshes according to the objectives to been achieved. Digital manufacturing is therefore sensitive to the amount of information that is obtained from a $3 \mathrm{~d}$ scan.
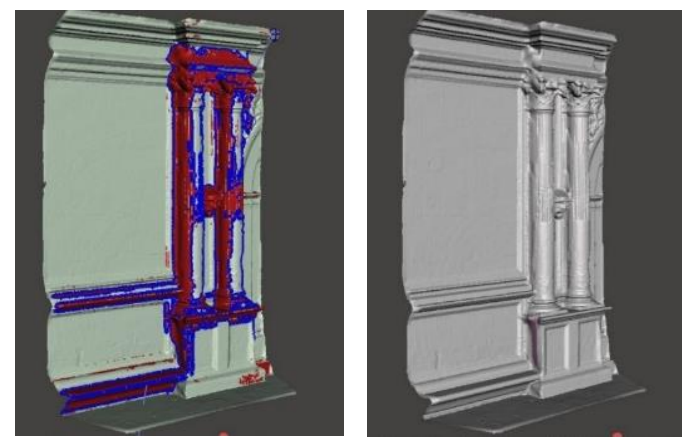

Figure 2: Digital reparation from 3dscanning, 2017

Later, it has been proceeded to build scale models of these examples (Figure 3 and 4), making multiple possible alternatives for the preservation and replication of these buildings. A series of questions are extracted, such as: what can be analyzed and preserved, what data be obtained, how to post-produce that information, how to build replicas at scale, and the put into question which of this information and how it could be made public for its dissemination.
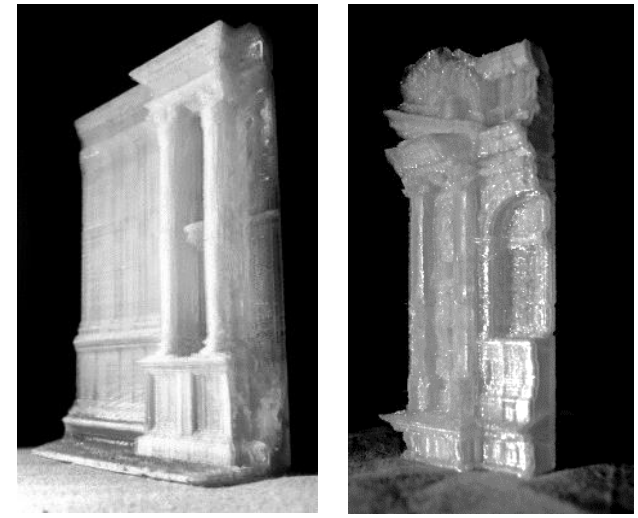

Figure 3: $3 \mathrm{~d}$ printed fragments of the façade. FDM print in PETG plastic, 2017.

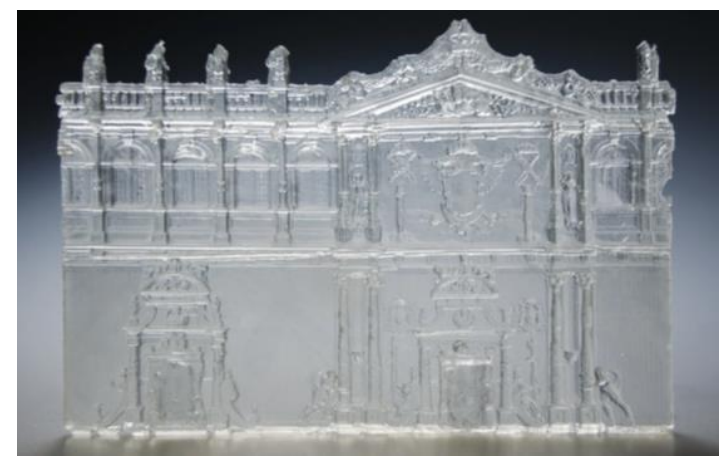

Figure 4: 3d printed fragment of the façade.

SLA print with clear resin, 2017.

\section{DEVELOPED METHODOLOGY}

\subsection{Case of study}

The funerary complex (Figure 5) was built 4000 years ago in Thebes, Egypt, and began to be excavated between 1910-1911, by Howard Carter, and then by Herbert Winlock in the 1920s in the name of the Metropolitan Museum of Art to reveal the secrets 
of funeral monuments (Morales et al, 2017). Western museums, which organized these missions to obtain antiques for their collections, discovered the complexity of these excavations. One hundred years later, the archaeological project of the Middle Kingdom of Thebes, by the University of Alcala, aims to document, understand and publish all these monuments and findings left by previous expeditions.

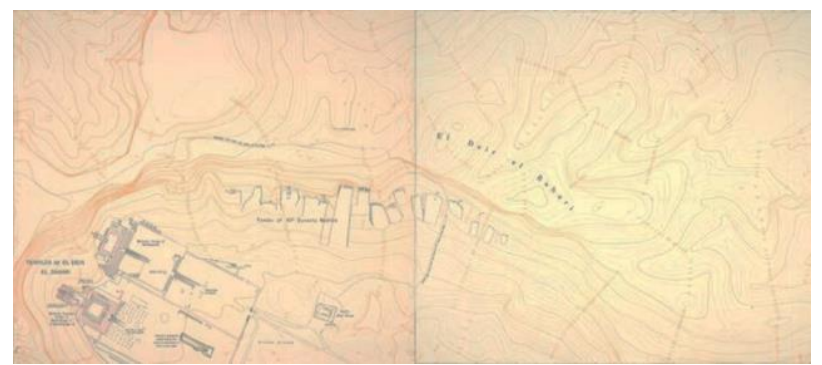

Figure 5: The Funerary Complex of Thebes, Luxor, Egypt.

In the third stage of this project, carried out by the staff of the University of Alcala (Figure 6), during the months of March and April of 2017, the Ipi tomb (TT 315) was cleaned, which is analyzed on this paper, the real treasure of Henenu (TT313) and the exterior patios that give access to those points

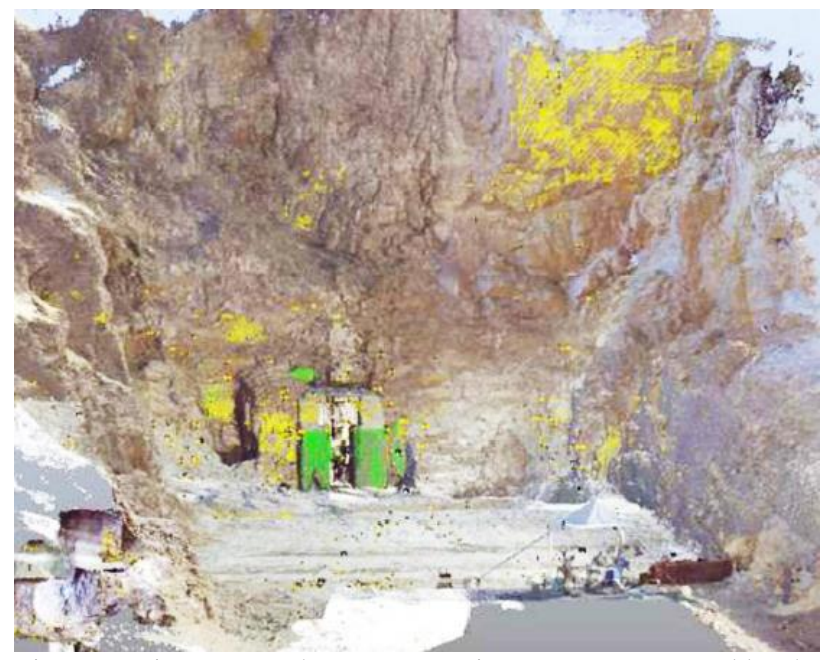

Figure 6: First approaches to excavation. Image generated by the 3d scanner from access to the funeral complex, 2017.

\subsection{Computational work}

The point cloud was obtained from a Faro scanner. The workflow follows different phases with, Faro Scene: The scanned spaces are imported and merged into one, forming a point cloud composed of different files. Secondly, a region of the point cloud, called Clipping Box, is selected to isolate the area to work. Next, the 3D mesh would be created. In this case, it is chosen the points that are interesting and export them to the format * .pts or *. e57, to subsequently post-produce the model in Autodesk ReCap.

Next, in ReCap, from now on as main work software, it can be seen that all the information of the Faro Scene, the commercial software of the scanner, remains. The scan name and position of scans, as well as the information of each point, with its color information, remains (Figure 7). From this software, it can be manually deleted points and prepare the surface from that it is to be acquired to be a 3D mesh: The unnecessary information is eliminated, then the information is uploaded to the Autodesk cloud, and finally, the $3 \mathrm{~d}$ mesh is generated in the servers.

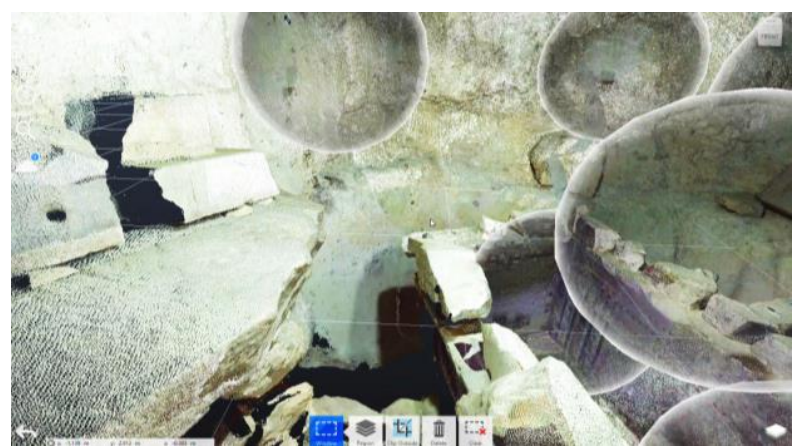

Figure 7: Position of the scanned and result of the scanner. Point cloud, 2018.

Once the procedure is finished, The file from Autodesk cloud is downloaded in the format *.obj. Thanks to this procedure, it is not necessary to have a high-performance computer, since the most exhaustive work, generating the $3 \mathrm{D}$ mesh, is done on the Autodesk servers themselves. So far, this procedure is free.

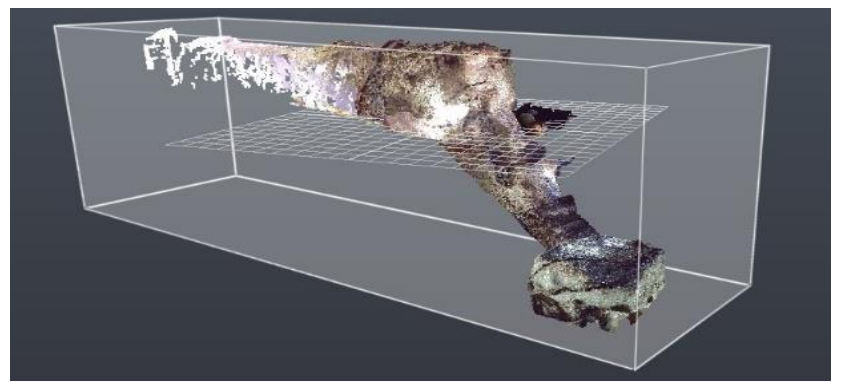

Figure 8: Access to the Ipi's sarcophagus. Final scan, 2018.
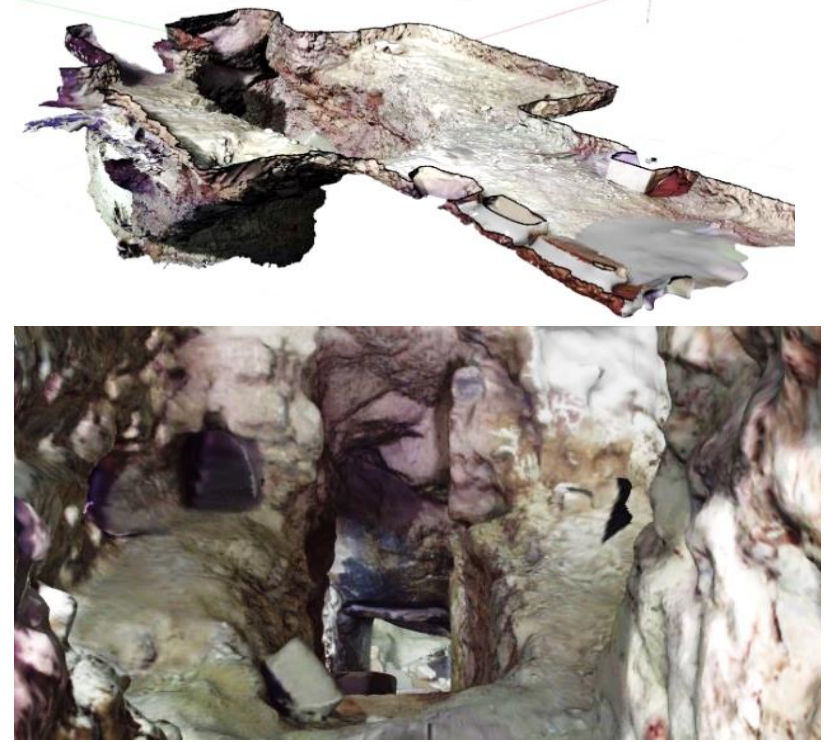

Figure 10 and 11: Access to the Ipi's sarcophagus.

Final model of the $3 \mathrm{~d}$ scan, 2018.

When a continuous $3 \mathrm{~d}$ mesh is achieved, it proceeds to elaborate post-processing files. There are numerous mesh editing software mentioned previously, such as 3dsMax, Maya, Zbrush. For this research, it was used Meshmixer again since it is free and intuitive software. With it, closed objects are generated to print in 3D. When importing the file, it can be seen that also conserves the original color information of the scanned space itself, in this way it could even be printed in 3D with colors with SLS technology. 


\subsection{Post-processing}

To post-process the object, it is started from the original 3D file, even with 3D errors, but continuous, to achieve the optimal 3D file for its manufacture: To organize it, it is selected faces of the mesh that contain errors, and is proceed to eliminate them using the component Clean Mesh native on Rhino or using again Meshmixer manually (Figure 8). Empty gaps and "shadow" areas of the scan are filled. With the brush tools, it can be generated new meshes or merely inspect the gaps and close them. It is selected the entire 3D object and proceed to perform an offset to give thickness. This procedure is the one that consumes the most resources of the computer.

Later make specific cuts with a 3D plane are made to fine-tune the thickness of the offset and regularize it. A new analysis is performed to find open gaps in the mesh and close them. The closed and repaired model is exported in * .stl or * .obj. If more definition is needed, or on the contrary, the file has an excessive volume, the software Grasshopper is used to increase the rugosity by extending the distance of the mesh vertex through the normals. Once the closed and sealed 3D model is finished, any native 3D printing software can be used for manufacturing. Depending on the machine or robot a different procedure has to be done. In this case, a commercial software Simplify3D is used.

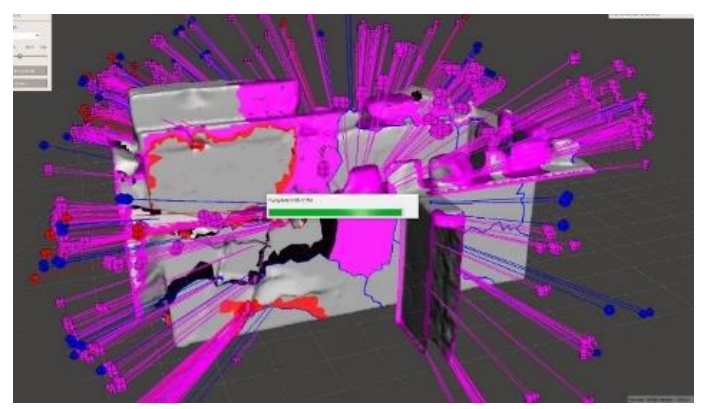

Figure 8: Post-processing mesh. Cleaning, 2018.

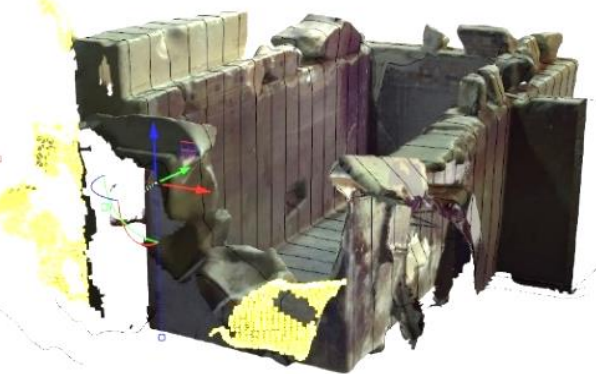

Figure 9: Post-processing mesh. Cleaning alternative through regenerating the geometry with a parametric algorithm, 2018

To compare this process, an additional workflow it is proposed including new software to the equation, which gives us the possibility of creating $3 \mathrm{~d}$ models with better mesh orientation. Although this type of process can be automated with commercial software, the alternative presented here is to create an additional mesh, based on the geometry of the existing one. Grasshopper is used to apply a transformation to the mesh in to divide it into equidistant segments (Figure 9), along with user-defined vectors. In this way cuts are made in the $\mathrm{X}, \mathrm{Y}$ and $\mathrm{Z}$ direction, to later rejoin them generating a more flexible $3 \mathrm{~d}$ model.

Following the concepts presented here, the three-dimensional files became necessary to document these archaeological sites are generated (Figures 10,11, 12 and 13). As a methodology, 3D meshes are used to create solid objects from which to produce scale models through digital fabrication. In this work, the final results of the repaired meshes, sections, and separate elements, and the production of $3 \mathrm{D}$ printing scaled models.
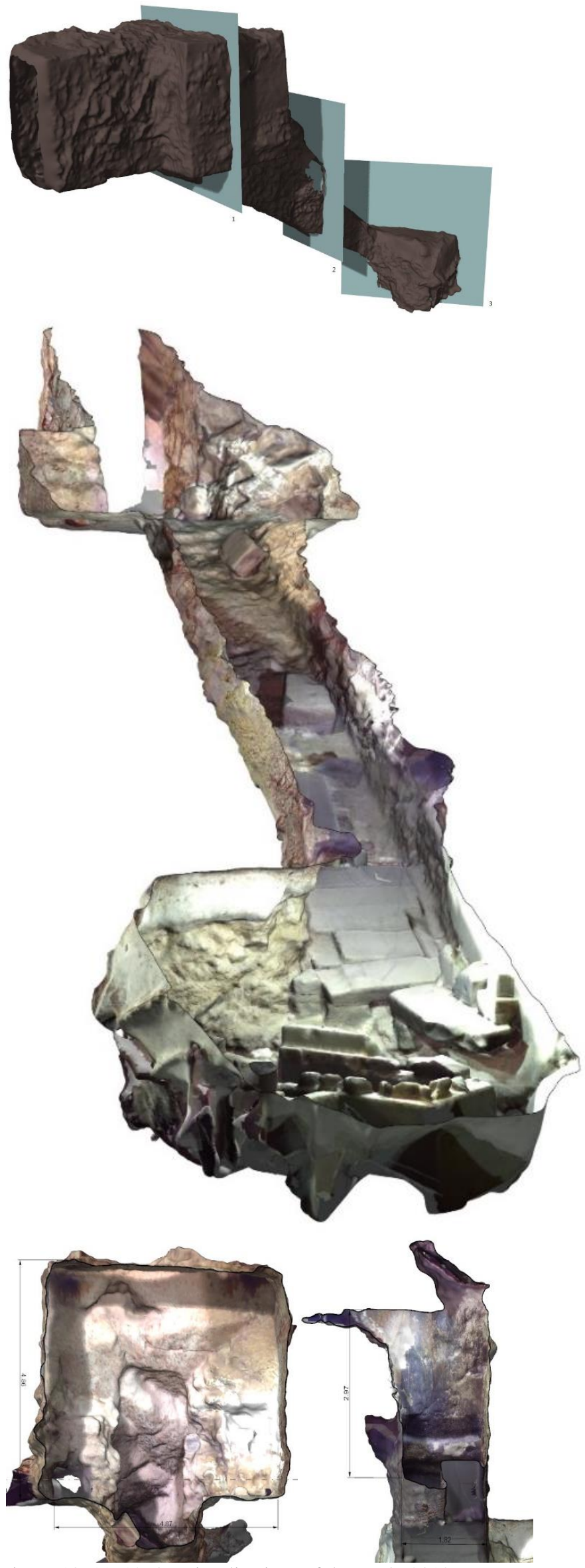

Figure 10, 11, 12: 3D visualizations of the tomb, 2018. 


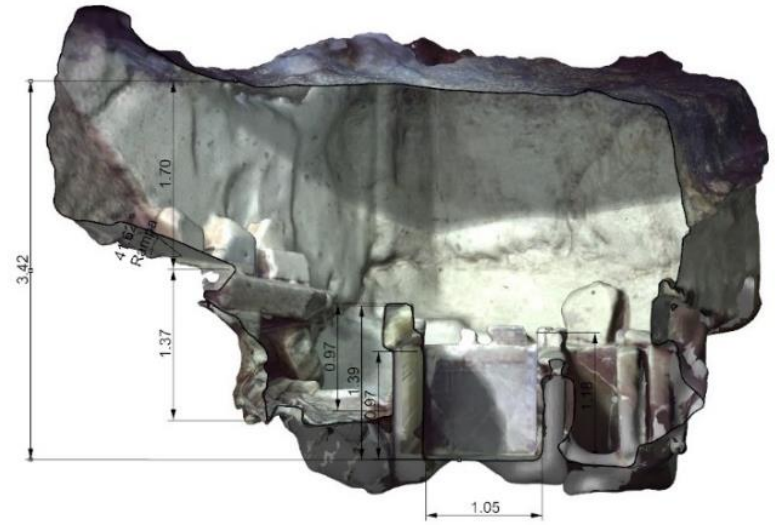

Figure 13: 3D visualizations of the tomb, 2018.

\section{PROTOTYPING AND DIGITAL FABRICATION}

Finally, having done all the work of computing to obtain the final mesh, the possibilities of manufacturing prototypes or scale models are analyzed. Thanks to the proposed workflow thickening tasks or boolean operations to generate models for manufacturing can be performed

The main advantage of this method it is to make changes in the parameters to adapt the desired resolution, for the additive manufacturing it ease the generation of lines of code. On the other hand, if it is willing to manufacture the object through CNC milling, this process speeds up the generation of Gcode, simplifying and avoiding the software that generates them, to access internal or flipped faces of the mesh.

To prove the digital results, the fabrication of scaled models with SLS and SLA technology is carried out, demonstrating that highresolution files can be obtained in light files.

It is important to note that the possibility of creating a thickening of the mesh in a regular and uniform way, allows using less material, without creating internal voids that store resin in SLA or nylon powder in SLS.

Additionally, the fabrication of a full-scale prototype of the sarcophagus is suggested (Figure 18), through sections, manufactured by additive manufacturing. To carry out this fabrication, $\mathrm{CNC}$ contours are proposed in $2 \mathrm{D}$, which also serve as the basis for the manufacture of the walls and floors of the sarcophagus, and finally, the sections are joined together.

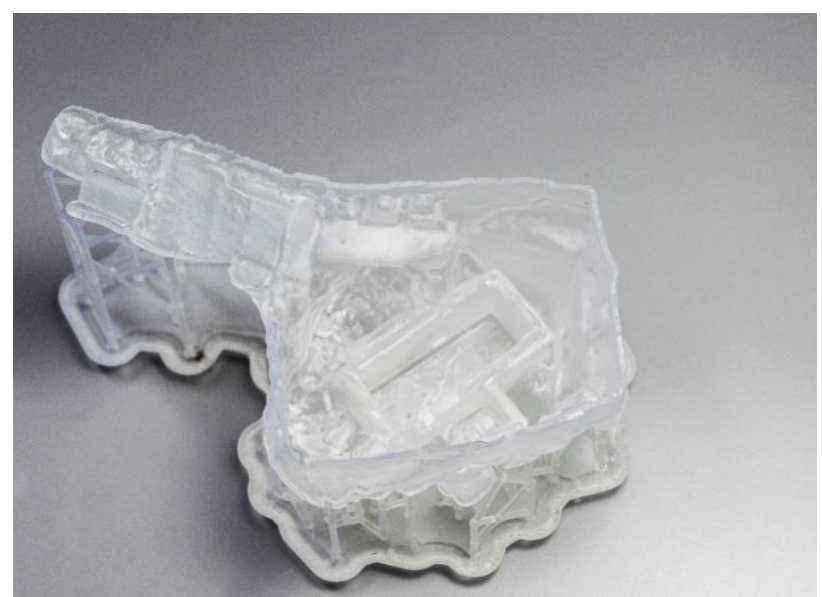

Figure 14: Model of the tomb of Ipi, Sarcophagus.

SLA Resin 3D printed model. 90 x 90 x 60 mm., 2018.

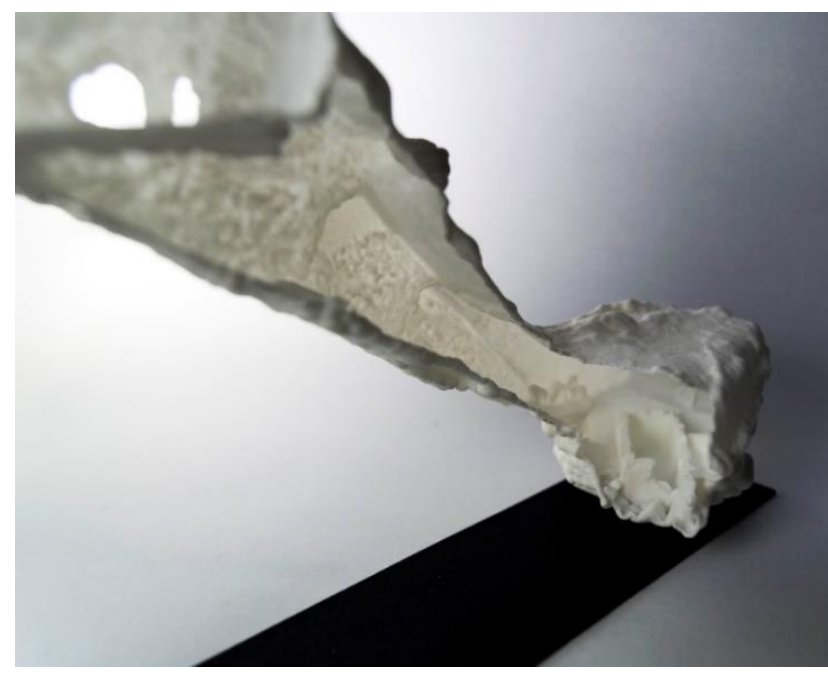

Figure 15: Model of the tomb of Ipi. General view. SLS Nylon 3D printed model. 150 x 65 x 95 mm., 2018.
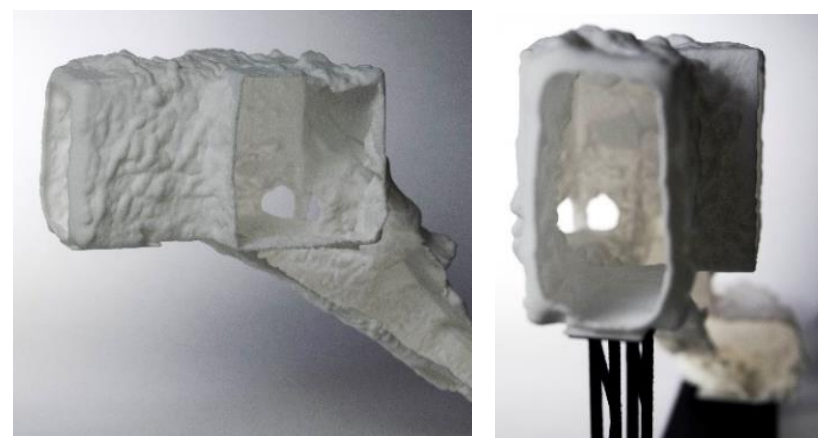

Figure 16 and 17: Model of the tomb of Ipi. Access view. SLS Nylon 3D printed model, 2018

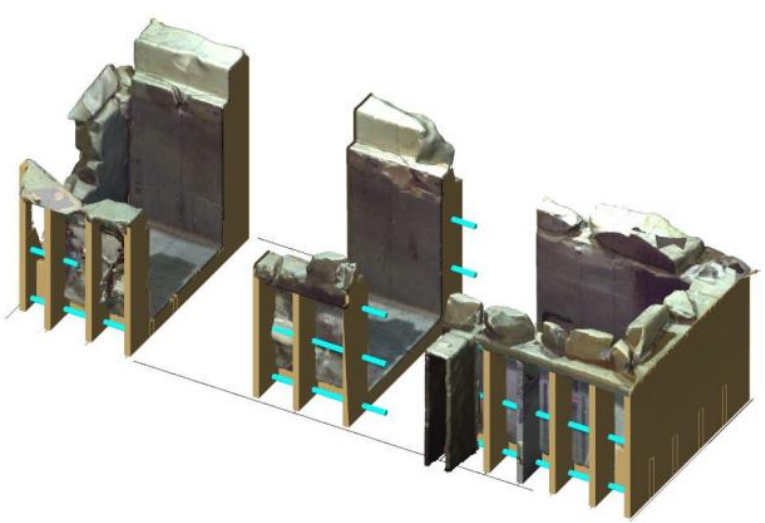

Figure 18: The tomb of Ipi. Sarcophagus.

1:1 Scale proposal. 2 x 1.5 x 1.2 m., 2018 .

\section{CONCLUSIONS}

The use of digital tools, such as 3D scanning, basically allows us to document numerous artistic and cultural projects, preserve them digitally for future generations, build replicas or even restore elements. Simulations of scanned architectural structures can be carried out, formulate hypotheses about their construction, and reach inaccessible places, in the case of archaeological excavations, and taking measurements on digitally protected elements, or going through the spaces virtually.

Thus, the process starts from superficial information of the scanned bodies. Also, empty spaces (shadows) are generated that have to be filled and repair in 3D, losing information of the real object. So it cannot be documented the entire object, but allowing 
the specialists to interpret what is not visible. Also, more specialized exploratory techniques such as computed tomography (CT) or X-ray could be used to obtain information deeply.

Digital storage gives us the possibility of recreating those spaces, through 3D models in an objective way, or Virtual Reality, by individually going through them; also generating scale models of spaces, even producing objects that facilitate the repair of lost elements. It can be said that thanks to the new three-dimensional scanning technologies 3D information can be stored firstly, to be analyzed for its dissemination in the future. On the other hand, the versatility that can be obtained through a three-dimensional file put into question what is the real value of physical, artistic objects. With projects like Nefertiti Hack (Nelles et al. 2016), it has been seen how collective knowledge can be enriched through the free publication of these $3 \mathrm{D}$ documents on web platforms, democratizing the cultural heritage.

To sum up, this method complements the information that specialists such as archaeologists can use, making decisions and refining the path they wish to take to analyze an unknown space. Although one of the main objectives of the research work has been to present a workflow to deal with 3 dscanning to digital fabrication, it can be noticed that due to the complexity, specialization in $3 \mathrm{D}$ postproduction it is required.

\section{DATA AVAILABILITY}

The datasets generated and analyzed during the current study are available from the corresponding authors on reasonable request.

\section{ACKNOWLEDGMENTS}

The authors would like to acknowledge the on working Middle Kingdom Theban Project (http://thebanproject.com/) for providing the used $3 \mathrm{~d}$ scan and the resources of the excavations.

\section{REFERENCES}

BRYCE, E., 2015. Reprinting history. (The British Museum uses 3D scanning to bring artifacts to life), WIRED: http://www.wired.co.uk/article/reprinting-history

British Museum Repository,

https://sketchfab.com/britishmuseum (Last accessed on Dec 2018)

Echeverria, E., Castaño, E., Casa. F., Celis, F., Chias, P., 2017. Documental Studio and 3D recreation of the San Ildefonso's School Facade, Alcalá de Henares, The International Archives of the Photogrammetry, Remote Sensing and Spatial Information Sciences, Volume XLII-2/W3, 2017 3D Virtual Reconstruction and Visualization of Complex Architectures, 1-3 March 2017, Nafplio, Greece.

Echeverría, E., Casa, F., Celis, F., and Chias, P., 2013. The University of Alcala de Henares (Madrid, Spain), as a dynamic example and laboratory of the recovery, rehabilitation, and conservation of the cultural heritage. ISPRS Archives Volume XL-5/W2. 2-6 September. pp., 237-243.

Furness, D., 2017. The British Museum publishes the first 3D scan of the Rosetta Stone online, Digital Trends: https://www.digitaltrends.com/cool-tech/3d-scan-rosetta-stone/ (Last accessed on Dec 2018)
García de Miguel, J.M., 2013. Estudio petrológico de la fachada principal del colegio Mayor de San Ildefonso y de las del Patio de Santo Tomas de Villanueva. Restauración contemporánea. Ciudades universitarias, ciudades Patrimonio de la Humanidad. La manzana fundacional Cisneriana de la Universidad de Alcalá. Ed. Universidad de Alcalá, Alcalá de Henares, pp. 527-550.

Lowe, A., 2017. Digital Recording in a time of Iconoclasm, Mass Tourism, Celebrity Culture and Anti-Ageing, British Council: http://www.factum-

arte.com/resources/files/fa/articles/2017/British_Council_webve rsion_Text_Digital_Recording_in_a time.pdf (Last accessed on Dec 2018)

Morales, Antonio J. et al., 2017. The Middle Kingdom Theban Project. Preliminary report on the University of Alcalá Expedition to Deir el-Bahari. Third Season (2017), Studien zur Altägyptischen Kultur 46, 153-190.

Nelles. N, 2016, The Other Nefertiti, Venice Architectural Biennale 2016: https://www.alloversky.com/The-Other-Nefertiti (Last accessed on Dec 2018)

Morales, Antonio J. et al., 2016. The Middle Kingdom Theban Project. Resultados preliminares de la Misión FUB en Deir elBahari. Primera y segunda campañas (2015-2016), Boletín de la Asociación Española de Egiptología 25, pp., 89-112.

Morales, Antonio J. et al,. 2016. The Middle Kingdom Theban Project. Preliminary report on the Freie Universität Berlin Mission to Deir el-Bahari. First and Second Seasons (20152016), Studien zur Altägyptischen Kultur 45, pp., 257-282

Rivera, J. et al., 2015. Universidad de Alcalá. Patrimonio de la Humanidad, $3^{\mathrm{a} e d, ~ A l c a l a ́ ~ d e ~ H e n a r e s . ~ I S B N: ~ 978-84-166599-76-~}$ 9

Rodriguez Navarro, P. (2012). La fotogrametría digital automatizada frente a los sistemas basados en sensores $3 \mathrm{~d}$ activos, Ega Expresión Gráfica Arquitectónica. N.20, p 100-111, $\begin{array}{llll}\text { sep. } & 2012 . & \text { ISSN } & 254-6103\end{array}$ https://polipapers.upv.es/index.php/EGA/article/view/1408 (Last accessed on Dec 2018)

Takehiko, N., 2013, MIT Course, 4.s53 Palladio Digitale. http://cat2.mit.edu/palladio/i_palladio_at_mit/

(Last accessed on Dec 2018)

Wachowiak, M. J. and Karas, B. V., 2009. 3d scanning and replication for museum and cultural heritage applications Journal of the American Institute for Conservation, Volume 48, 2009, Issue 2

https://www.si.edu/content/MCIImagingStudio/papers/scanning _paper.pdf (Last accessed on Dec 2018) 